\title{
Enhanced Antibacterial Effect of Titanium Dioxide Nanoparticles Mediated Grape Seed Extract on Oral Pathogens - Streptococcus mutans and Lactobacillus
}

\author{
Ramya G. ${ }^{1}$, Arvina Rajasekar ${ }^{2}$ \\ 1,2 Department of Periodontics, Saveetha Dental College, Chennai, Tamilnadu, India.
}

\section{ABSTRACT}

\section{BACKGROUND}

Streptococcus mutans is the primary pathogen responsible for initiating dental caries and decay. Lactobacilli present in caries lesions is a major contributor to caries progression. Titanium dioxide nanoparticles have been found to have a large spectrum of activity against microorganisms. The grape seed extract has been shown to have inhibitory effects against several clinically important microbes. This study was conducted to assess the enhanced antibacterial effect of titanium dioxide nanoparticles mediated grape seed extract against oral pathogens, S. mutans and lactobacillus.

\section{METHODS}

This experimental study was done by preparing the grape seed extract, synthesising titanium dioxide (TiO2) nanoparticles, preparing the nanoparticles powder, and then evaluating the antibacterial activity of nanoparticles against lactobacillus species and Streptococcus mutans.

\section{RESULTS}

The peak found in the spectroscopy indicates the formation of titanium dioxide nanoparticles. The zone of inhibition for antibiotics enhanced with $50 \mu \mathrm{l}, 100 \mu \mathrm{l}, 150$ $\mu \mathrm{l}$ of grape seed mediated TiO2 nanoparticles were $16 \mathrm{~mm}, 18 \mathrm{~mm}$ and $19 \mathrm{~mm}$ in Streptococcus mutans. In lactobacillus species the zone of inhibition for standard antibiotics enhanced with $50 \mu \mathrm{l}, 100 \mu \mathrm{l}, 150 \mu \mathrm{l}$ of grape seed mediated TiO2 nanoparticles remained constant at $35 \mathrm{~mm}$.

\section{CONCLUSIONS}

The titanium dioxide nanoparticle mediated grape-seed extract showed excellent antimicrobial activity against lactobacillus and Streptococcus mutans. This proves that in future it can be used for treating these bacterial infections in the oral cavity after further in vivo studies.

\section{KEY WORDS}

Nanotechnology, Titanium Dioxide Nanoparticles, Grape Seed Extract, Lactobacillus, Enhanced Antibacterial, S. mutans
Corresponding Author: Dr. Arvina Rajasekar, Department of Periodontics, Saveetha Dental College,

Chennai, Tamilnadu, India.

E-mail: draravina92@gmail.com

DOI: $10.14260 / \mathrm{jemds} / 2021 / 344$

How to Cite This Article:

Ramya G, Rajasekar A. Enhanced antibacterial effect of titanium dioxide nanoparticles mediated grape seed extract on oral pathogens-Streptococcus mutans and Lactobacillus. J Evolution Med Dent Sci 2021;10(22):1656-1661, 10.14260/jemds/2021/344

Submission 07-10-2020,

Peer Review 07-04-2021,

Acceptance 13-04-2021,

Published 31-05-2021.

Copyright (c) 2021 Ramya G. et al. This is an open access article distributed under Creative Commons Attribution License [Attribution 4.0 International (CC BY 4.0)] 


\section{BACKGROUND}

Nanotechnology is an interdisciplinary field that is undergoing rapid development and materialising, it has brought about enormous changes in the field of dentistry especially. Nanotechnology has demonstrated to have different applications in dentistry, including dentition renaturalisation, treatment for dentin hypersensitivity, complete orthodontic realignment in a solitary visit etc. ${ }^{1-3}$

The adjunct 'nano' originated from the Greek word nanos, meaning dwarf, and describes substances whose molecular size lies in the range of 0 to 100 nanometres. The concept of nanomedicine was first introduced by Robert A Frietas, Jr. in 1993 and was defined, as follows: Nanomedicine is the preservation and improvement of human health using molecular tools and molecular knowledge of the human body. It has diversified actions ranging from target drug delivery to creating tissue scaffolds based on nanoscale molecules. ${ }^{4-8}$

Streptococcus mutans is a microbe that has been strongly associated with the initiation of dental caries, studies also show that lactobacilli may be more significant in the progression of caries lesions and have found it to be responsible for the initiation of a low percentage of coronal caries. ${ }^{9-11}$ Lactobacilli adheres poorly to oral tissue and is normally present either in low numbers or absent in healthy mouths, but increased in sites of active caries, particularly carious dentine. 12

Grape seeds due to their phenolic components and good antioxidant properties possess the ability to benefit the health of an individual in various ways including treating tooth decay, protecting against pathogens, improving night vision, treating diabetic retinopathy and improving blood sugar control, reducing oedema, reducing iron levels in people with haemochromatosis, reducing inflammation. ${ }^{13}$ Grape seed extract is a readily available plant-based supplement that, due to its concentrated levels of proanthocyanidins, has promising characteristics that may assist in dental caries prevention via its antibacterial and antioxidant properties. ${ }^{14,15}$

The widespread use of antibiotics has led to the emergence of multidrug-resistant bacterial strains. The search for new antimicrobial substances has been engaged toward metal oxide nanoparticles. ${ }^{16,17}$ Specifically, titanium oxide has been considered as an attractive antimicrobial compound due to its photocatalytic nature and because it is a chemically stable, non-toxic, inexpensive and recognised as a biocompatible substance. ${ }^{18-20}$ Several studies have revealed this metal oxide demonstrates excellent antifungal and antibacterial properties against a broad range of both gram-positive and gram-negative bacteria. ${ }^{21,22}$ These properties were significantly improved by titanium oxide nanoparticles synthesis.

Nanotechnology has gigantic potential, yet issues, for example, open acknowledgment, morals, guidelines, and human well-being must be considered before subatomic nanotechnology can be viewed as a chance of giving great dental care. ${ }^{23,24}$

The aim of the study was to assess the enhanced antibacterial effect of $\mathrm{TiO} 2$ nanoparticles mediated grape seed extract against oral pathogens, S. mutans and lactobacillus.

\section{METHODS}

The study was done under laboratory setup and in the premises of Saveetha Dental College. It was an experimental study conducted from December 2019 to January 2020.

\section{Preparation of the Grape Seed Extract}

The collected grape seeds were rinsed for 4 - 5 times in distilled water and dried for 8 - 15 days. The well dried grape seeds were powdered. The powdered grape seed was stored in air- tight containers. In a beaker, $0.5 \mathrm{~g}$ of grape seed powder was added to $100 \mathrm{ml}$ of distilled water and mixed well. Then boiled for 10 mins at $70-80^{\circ} \mathrm{C}$. The solution was allowed to cool and then filtered by using Whatman no. 1 filter paper and funnel. Freshly prepared grape seed extract was thus obtained.

\section{Synthesis of TiO2 Nanoparticles}

$65 \mathrm{ml}$ of $0.4 \mathrm{~g}$ TiO2 was prepared using distilled water. It was added to the freshly prepared grape seed extract and made into $100 \mathrm{ml}$ solution with distilled water. It was mixed well by placing in a magnetic stirrer in an orbital shaker for 10 hours. The absorbance was measured using ultraviolet UV-visible spectrometer on regular intervals to confirm the presence of TiO2 nanoparticles formed. The colour change was noted and reading was taken every 2 hours. The final reaction mixture was centrifuged for 10 mins at $4000 \mathrm{rpm}$ using Lark refrigerated centrifuge. It was then collected and stored in an air-tight Eppendorf tube (Figure 1).

\section{Enhanced Antibacterial Activity}

The agar well-diffusion method was used to determine the enhanced antibacterial activity of $\mathrm{TiO} 2$ nanoparticles. Different TiO2 concentrations were tested against lactobacillus species and Streptococcus mutans (grampositive). Concentrations of $50 \mu \mathrm{l}, 100 \mu \mathrm{l}, 150 \mu \mathrm{l}$ of grape seed mediated $\mathrm{TiO} 2$ nanoparticles were placed inside the wells. Then the agar plates were incubated at $37^{\circ} \mathrm{C}$ for 24 hours. The standard antibiotics and the prepared particles were together used to test the enhanced effect of the synthesised grape seed mediated $\mathrm{TiO} 2$ nanoparticles on the bacterial species. In each plate, the zone of inhibition was recorded (Figure 2, 3).

\section{RESULTS}

From the table, the zone of inhibition for antibiotics enhanced with $50 \mu \mathrm{l}, 100 \mu \mathrm{l}, 150 \mu \mathrm{l}$ of grape seed mediated TiO2 nanoparticles were $16 \mathrm{~mm}, 18 \mathrm{~mm}$ and $19 \mathrm{~mm}$ in Streptococcus mutans. In lactobacillus species the zone of inhibition for standard antibiotics enhanced with $50 \mu \mathrm{l}, 100 \mu \mathrm{l}$, $150 \mu \mathrm{l}$ of grape seed mediated $\mathrm{TiO} 2$ nanoparticles remained constant at $35 \mathrm{~mm}$. (Table 1). 

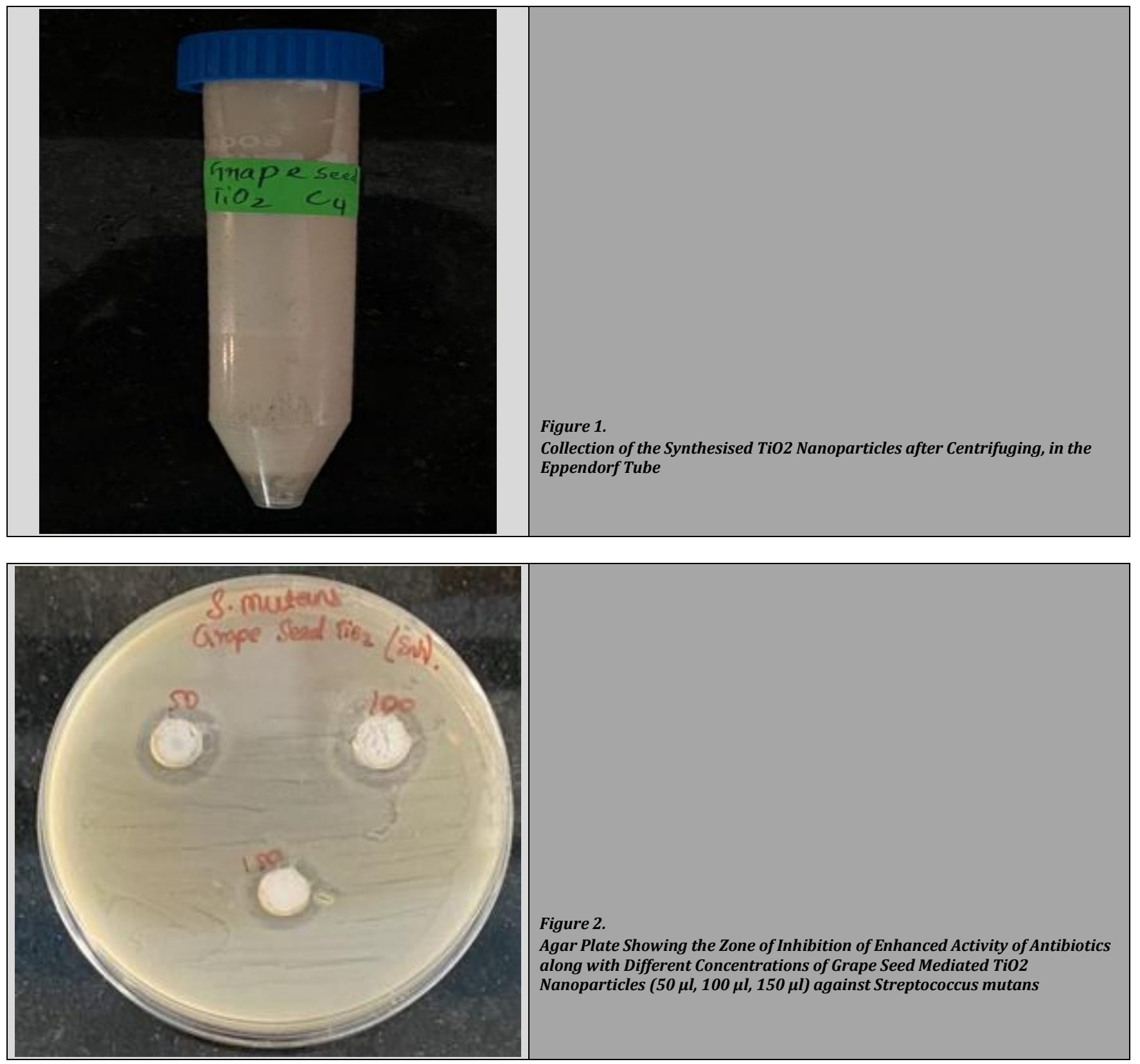

Figure 2.

Agar Plate Showing the Zone of Inhibition of Enhanced Activity of Antibiotics along with Different Concentrations of Grape Seed Mediated TiO2

Nanoparticles ( $50 \mu \mathrm{l}, 100 \mu \mathrm{l}, 150 \mu \mathrm{l}$ ) against Streptococcus mutans

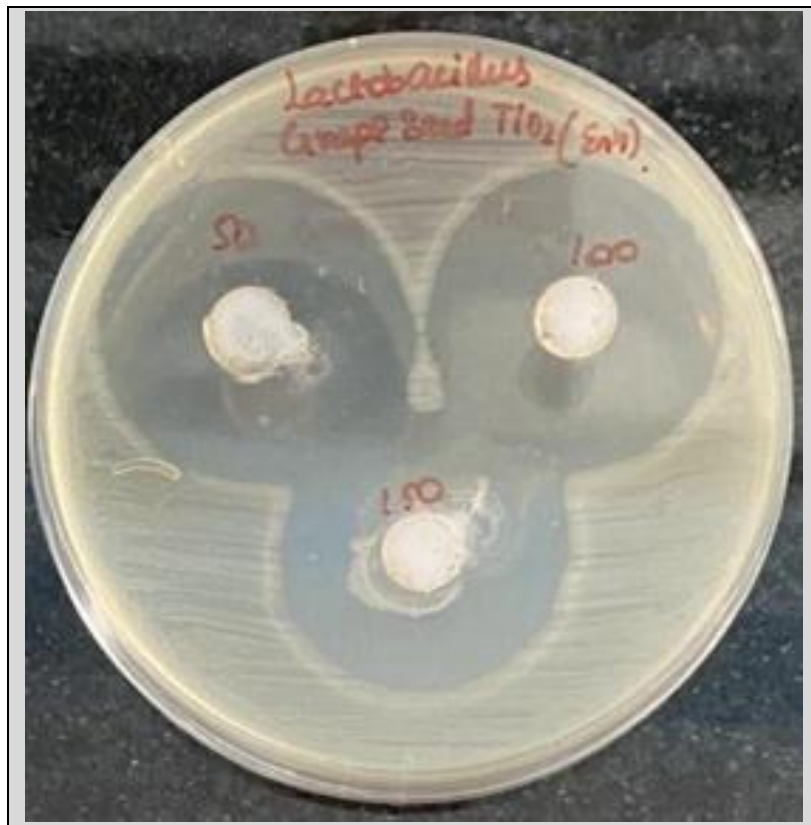

Figure 3.

Agar Plate Showing the Zone of Inhibition of Enhanced Activity of Antibiotics

along with Different Concentrations of Grape Seed Mediated TiO2

Nanoparticles (50 $\mu \mathrm{l}, 100 \mu \mathrm{l}, 150 \mu \mathrm{l})$ against Lactobacillus Species 


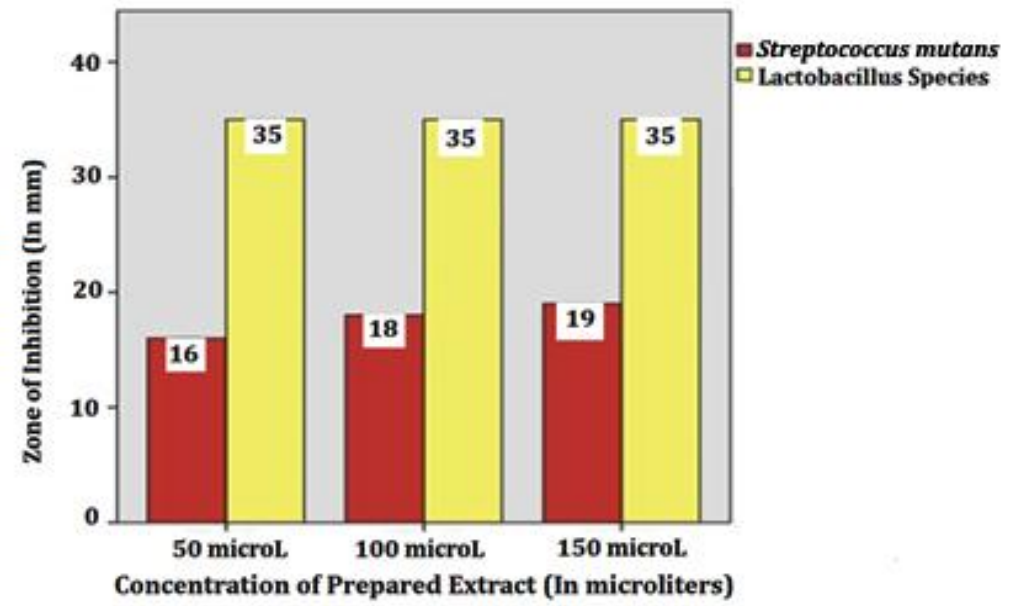

Figure 4. Graph Depicting the Enhanced Antibacterial Activity of Grape Seed Mediated Titanium Dioxide Nanoparticles against Streptococcus mutans and Lactobacillus Species as Observed in This Study

Enhanced Antibacterial Activity of Grape Seed Mediated Titanium Dioxide Nanoparticles

\begin{tabular}{|ccc|}
\hline $\begin{array}{c}\text { Concentration of the } \\
\text { Prepared Extract. }\end{array}$ & \multicolumn{2}{c|}{ Zone of Inhibition in mm. } \\
$50 \mu \mathrm{l}$ & 35 & 16 \\
$100 \mu \mathrm{l}$ & 35 & 18 \\
$150 \mu \mathrm{l}$ & 35 & 19 \\
\hline \multicolumn{2}{|c|}{ Table 1. Table Depicting the Zone of Inhibition } \\
& as Observed in This Study \\
\hline
\end{tabular}

\section{DISCUSSION}

Titanium dioxide has become part of our everyday lives. It is found in various consumer goods and products of daily use such as cosmetics, paints, dyes and varnishes, textiles, paper and plastics, food and drugs and even paving stones. ${ }^{25-27}$ The great versatility of titanium dioxide is owing to its various forms and sizes. ${ }^{28}$ Titanium dioxide NPs have been explored for a variety of biomedical applications.

Studies performed previously by Maryam revealed that metal oxide nanoparticles such as titanium dioxide nanoparticles also show significant antimicrobial activity through connection to microbial deoxyribonucleic acid (DNA) and proteins, and are caused to prevent bacterial duplication, avoiding metabolic enzymes of the bacterial electron transport chain leading to their inactivation.29-31 According to Zhang, TiO2 nanoparticles can be selected as an antibacterial material because of their superior properties, such as high specific surface area and high activity to block a wide scope of pathogenic agents. ${ }^{32,33}$ Although titanium dioxide nanoparticles improve mechanical and antibacterial properties of conventional glass ionomer cements, their biocompatibility is still controversial. ${ }^{34}$

The oral cavity is continuously exposed to a lot of microorganisms. Plaque biofilm is a significant reason for caries, periodontitis and other dental problems. ${ }^{35}$ It comprises a complex network of microorganisms that cause various diseases. ${ }^{36}$ Lactobacillus species and Streptococcus mutans are the most significant oral microbes experienced in the arrangement of plaque biofilm causing dental caries and periodontal issues. ${ }^{37}$ This investigation advances the turn of events and utilisation of antibacterial nanoparticles in dentistry which incorporates therapeutic dentistry, periodontics, endodontics, implantology, dental prosthesis and orthodontics. ${ }^{38,39}$ This can prevent the activity of caries brought about by the microbial demineralisation and erosion activities. ${ }^{40}$ It can likewise be utilised as antibacterial irrigant or sealer in endodontics. ${ }^{41}$ There are many strategies in dentistry in which the antibacterial nanoparticles can be integrated. ${ }^{42}$

\section{CONCLUSIONS}

The antibacterial activity of grape seed mediated TiO2 nanoparticles was studied. Lactobacillus species and Streptococcus mutans were studied as they are closely associated with dental problems. Grape seed mediated TiO2 nanoparticles have enhanced antibacterial activity against lactobacillus species and Streptococcus mutans.

Data sharing statement provided by the authors is available with the full text of this article at jemds.com.

Financial or other competing interests: None.

Disclosure forms provided by the authors are available with the full text of this article at jemds.com.

\section{REFERENCES}

[1] Subramani K, Subbiah U, Huja S. Nanotechnology in orthodontics-1: the past, present and a perspective of the future. Nanobiomaterials in Clinical Dentistry 2019:27998. http://dx.doi.org/10.1016/b978-0-12-8158869.00011-5

[2] Calisir M. Nanotechnology in dentistry: past, present and future. Stem Cell Biology and Regenerative Medicine 2019:197-216. http://dx.doi.org/10.1007/978-3-03031202-2_7

[3] Kim S, Kwon K, Kwon IC, et al. Nanotechnology in drug delivery: past, present and future. Nanotechnology in Drug Delivery 2009:581-96. http://dx.doi.org/10.1007/978-0-387-77668-2_19

[4] AlKahtani RN. The implications and applications of nanotechnology in dentistry: a review. Saudi Dent J 
2018;30(2):107-16.

[5] Hansa K, Basavaraj P, Singla A, et al. Implications of nanotechnology in dentistry. Journal of Orofacial and Health $\quad$ Sciences 2014;5:6. http://dx.doi.org/10.5958/2229-3264.2014.00192.0

[6] Verma S, Chevvuri R, Verma S. Nanotechnology in dentistry: unleashing the hidden gems. J Indian Soc Periodontol 2018;22(3):196-200.

[7] Neel EAA, Bozec L, Perez RA, et al. Nanotechnology in dentistry: prevention, diagnosis and therapy. Int J Nanomedicine 2015;10:6371-94.

[8] Panchbhai A. Nanotechnology in dentistry. Applications of Nanocomposite Materials in Dentistry 2019:191-203. http://dx.doi.org/10.1016/b978-0-12-813742-0.000122

[9] Caufield PW, Schön CN, Saraithong P, et al. Oral lactobacilli and dental caries: a model for niche adaptation in humans. J Dent Res 2015;94(9 Suppl):110S-8S.

[10] Caufield PW, Li Y, Dasanayake A, et al. Diversity of lactobacilli in the oral cavities of young women with dental caries. Caries Res 2007;41(1):2-8.

[11] Forssten SD, Björklund M, Ouwehand AC. Streptococcus mutans, caries and simulation models. Nutrients 2010;2(3):290-8.

[12] Badet C, Thebaud NB. Ecology of lactobacilli in the oral cavity: a review of literature. Open Microbiol J 2008;2:3848.

[13] Pezzuto JM, Venkatasubramanian V, Hamad M, et al. Unraveling the relationship between grapes and health. J Nutr 2009;139(9):1783S-7S.

[14] Ma ZF, Zhang H. Phytochemical constituents, health benefits and industrial applications of grape seeds: a mini-review. Antioxidants (Basel) 2017;6(3):71.

[15] Matthäus B. Virgin grape seed oil: is it really a nutritional highlight? European Journal of Lipid Science and Technology http://dx.doi.org/10.1002/ejlt.200700276

[16] Kandaswamy E, Nagendrababu V, Deivanayagam K. Antimicrobial effect of nanoparticles in endodontics. Nanobiomaterials in Dentistry 2016:161-86. http://dx.doi.org/10.1016/b978-0-323-42867-5.000151

[17] Kellen JA. Mechanisms of multidrug resistance. Alternative Mechanisms of Multidrug Resistance in Cancer 1995:1-30. http://dx.doi.org/10.1007/978-14615-9852-7_1

[18] Luque R, Varma RS, Clark JH. Sustainable preparation of metal nanoparticles: methods and applications. Royal Society of Chemistry 2012: p. 230.

[19] Janus M. Application of titanium dioxide. Intech Open 2017: p. 240.

[20] Lan Y, Lisfi A, Cook L. Titanium dioxide nanoparticles: characterization, properties and synthesis. 2017: p. 183.

[21] Madkour LH. Reactive Oxygen Species (ROS), Nanoparticles and Endoplasmic Reticulum (ER) StressInduced Cell Death Mechanisms. $1^{\text {st }}$ edn. Academic Press 2020: p. 780.

[22] Maity GN, Maity P, Choudhuri I, et al. Green synthesis, characterization, antimicrobial and cytotoxic effect of silver nanoparticles using arabinoxylan isolated from Kalmegh. Int J Biol Macromol 2020;162:1025-34.

[23] Allhoff F, Lin P. Nanotechnology \& society: current and emerging ethical issues. Science \& Business Media, Springer 2008: p. 300.

[24] Khan AS. Nanotechnology: ethical and social implications. $1^{\text {st }}$ edn. CRC Press 2012: p. 365.

[25] Shukla AK. Nanoparticles in medicine. Nature. $1^{\text {st }}$ edn. Singapore: Springer 2019: p. 220.

[26] Thota S, Crans DC. Metal nanoparticles: synthesis and applications in pharmaceutical sciences. $1^{\text {st }}$ edn. WileyVCH 2018: p. 265.

[27] Lekhadia DR. Nanotechnology in orthodontics-futuristic approach. Dental Applications of Nanotechnology 2018:155-75. http://dx.doi.org/10.1007/978-3-31997634-1_9

[28] Chaughule RS. Dental applications of nanotechnology. Switzerland: Springer Inernational Publishing 2018: p. 277.

[29] Azizi-Lalabadi M, Ehsani A, Divband B, et al. Antimicrobial activity of titanium dioxide and zinc oxide nanoparticles supported in 4A zeolite and evaluation the morphological characteristic. Scientific Reports 2019;9(1):17439.

[30] Kotlhao K, Madiseng MDT, Mtunzi FM, et al. The synthesis of silver, zinc oxide and titanium dioxide nanoparticles and their antimicrobial activity. Advanced Materials Proceedings 2017;2(8):479-84 http://dx.doi.org/10.5185/amp.2017/803

[31] Vega-Jiménez AL, Vázquez-Olmos AR, Acosta-Gío E, et al. In vitro antimicrobial activity evaluation of metal oxide nanoparticles. In: Koh KS, Wong VL, eds. Nanoemulsionsproperties, fabrications and applications. Rijecks, Croatia: IntechOpen 2019: $\quad$ p. $1-18$. http://dx.doi.org/10.5772/intechopen.84369

[32] Besinis A, Hadi SD, Le HR, et al. Antibacterial activity and biofilm inhibition by surface modified titanium alloy medical implants following application of silver, titanium dioxide and hydroxyapatite nanocoatings. Nanotoxicology 2017;11(3):327-38.

[33] Besinis A, De Peralta T, Handy RD. The antibacterial effects of silver, titanium dioxide and silica dioxide nanoparticles compared to the dental disinfectant chlorhexidine on Streptococcus mutans using a suite of bioassays. Nanotoxicology 2014;8(1):1-16.

[34] O'Mathuna DP. Nanoethics: big ethical issues with small technology. A \& C Black 2010: p. 248.

[35] Marsh PD. Plaque as a biofilm: pharmacological principles of drug delivery and action in the sub-and supragingival environment. Oral Dis 2003;9(Suppl 1):16-22.

[36] Marsh PD. Microbiologic aspects of dental plaque and dental caries. Dent Clin North Am 1999;43(4):599-614, vvi.

[37] Ikeda T, Sandham HJ, Bradley EL Jr. Changes in Streptococcus mutans and lactobacilli in plaque in relation to the initiation of dental caries in Negro children. Arch Oral Biol 1973;18(4):555-66.

[38] Moothedath M, Moothedath M, Jairaj A, et al. Role of nanotechnology in dentistry: systematic review. J Int Soc Prev Community Dent 2019;9(6):535-41.

[39] Sriram K, Vishnupriya V, Gayathri R. Review on the role of nanotechnology in dentistry and medicine. Research Journal of Pharmacy and Technology 2016;9(8):1249-52. http://dx.doi.org/10.5958/0974-360x.2016.00236.5

[40] Carrouel F, Viennot S, Ottolenghi L, et al. Nanoparticles as anti-microbial, anti-inflammatory and remineralizing 
agents in oral care cosmetics: a review of the current situation. Nanomaterials (Basel) 2020;10(1):140. http://dx.doi.org/10.3390/nano10010140

[41] Kishen A. Nanotechnology in endodontics: current and potential clinical applications. Springer International Publishing 2015: p. 199.
[42] De Dicastillo CL, Correa MG, Martinez FB, et al. Antimicrobial effect of titanium dioxide nanoparticles. In: Antimicrobial Resistance. London, U.K.: IntechOpen 2020. http://dx.doi.org/10.5772/intechopen.90891 